\title{
Editorial: Urban Sustainability Goals and the New Urban Agenda
}

\author{
Tathagata Chatterii* \\ School of Human Settlements, Xavier University, Bhubaneswar, India
}

Keywords: sustainable development goals, new urban agenda, urban sustainability, urban governance and management, goal setting

\section{Editorial on the Research Topic}

\section{Urban Sustainability Goals and the New Urban Agenda}

Taking into account the growing importance of the cities in global sustainability discourse, the Agenda for Sustainable Development (2030) adopted by the United Nations in 2015 has identified SDG 11 (Sustainable Cities and Communities) as a specific goal under the Sustainable Development Goals (SDG) framework. Subsequently, the Habitat III conference in 2016 adopted the New Urban Agenda, which calls upon the signatory countries to enhance urban planning, governance, and financial capacities of their cities to achieve sustainability targets. This special issue seeks to understand how urban sustainability goals and the NUA are unfolding across the globe.

From a conceptual standpoint, the SDG framework rests on the systems approach. There are two crucial attributes-governance through goal settings and synergy between goals. Normative targets of the SDGs are designed to facilitate administrative monitoring and act as a decision support system for policymakers (Hansson et al., 2019). For this purpose, the 17 global goals are sub-divided into 169 targets and 231 indicators (UN-Stats, 2015). The indicators set under different SDGs are also mutually interdependent upon each other, to encourage a more integrated approach toward development. Targets under the urban-centric SDG-11 overlaps with almost every other sustainability goal. Thus, by focusing on the city level it is possible to simultaneously address multiple sustainability concerns. For example, improvement in provision of basic amenities in slum areas under target SDG 11.1 can simultaneously contribute to improve health and well-being (SDG 3) of urban poor and thereby increase their earning capacities (SDG 1 - poverty reduction), besides improving access to water and sanitation (SDG 6).

City-level monitoring of various sustainability indicators can make our urban management processes more objective. However, the adaptation of the global sustainability goals at the city level faces several operational hindrances (Krellenberg et al., 2019; Giles-Corti et al., 2020). The sectoral SDG targets are often managed by agencies functioning under state and national governments. Bringing alignment in sustainability targets between such sectoral agencies and city governments require extensive coordination across multiple levels of governments-the modalities of which are shaped by local contextual arrangements (Zinkernagel et al., 2018). Furthermore, many cities do not have adequate financial and administrative capacity to undertake additional tasks involved in meeting SDG targets. The NUA sought to address these deficiencies and nudged the national governments to extend greater support toward their cities by framing national level urban policies. As envisaged under the NUA, national urban policies are not legally binding but are expected to emerge as institutional platforms to bring greater policy coordination between wide range of state and non-state actors involved in shaping urban sustainability outcomes, identification of priority areas for financial allocation, and building capacities at the local level. According to a recent UN Habitat report, 162 countries have formulated national urban policies, although there are considerable differences regarding forms, developmental stages and thematic focus of the policy documents (UN Habitat, 2021). 
However, with less than 10 years remaining, the world is far away from attaining the ambitious SDG agenda (United Nations, 2019, 2021). The SDG targets were already going offtrack in 2019, then the Covid-19 pandemic stuck and has introduced several new challenges. Six articles in this special issue focus on SDG implementation challenges from three distinct, yet mutually inter-related vantage points. These are methodological questions related to SDG target selections and progress monitoring; budgeting and financing; and roles of local actors.

The indicator-driven SDG framework is data intensive. An evidence-based decision support system that conceptually underpins the framework requires extensive data inputs to monitor the normative targets. However, detailed city-level data for many of the SDG indicators are often hard to come by Zinkernagel et al. (2018) and Giles-Corti et al., 2020. The problem is more acute in fast-growing cities of the Global South, where informalities are high and data gathering institutions are weak. City to city comparison is also frequently problematic, as the datasets are not standardized (Klopp and Petretta, 2017). The SDG framework is not legally binding. While this flexibility allows the cities to configure the global indicators as per local requirements, inter-city benchmarking also becomes difficult. The article by Hsu et al. has sought to address this challenge by framing a comprehensive Urban Environment and Social Inclusion Index (UESI) to compare the performance of 164 global cities in attaining progress toward SDG-11 targets. The framework includes two sets of indicators. The cities are globally compared regarding water stress and carbon dioxide emissions; while indicators like air pollution, urban tree cover, public transit access, and Urban Heat Island are applied to measure intra-city neighborhood level distribution of environmental stress.

Research by Ghosh et al. also applies Building Volume Per Capita (BVPC) as proxy measures to overcome data gaps related to SDG indicators in analyzing urban economic inequalities in nine Californian cities. They found that BVPC was inversely related with intensity of development, and positively related with median household income within cities. Barata et al. apply three different methodologies to compare temperature and precipitation projections for the city of Rio de Janeiro. Three alternative scenario projections based on different methods can inform the policymakers about different degrees of risks

\section{REFERENCES}

Giles-Corti, B., Lowe, M., and Arundel, J., (2020). Achieving the SDGs: evaluating indicators to be used to benchmark and monitor progress towards creating healthy and sustainable cities. Health Policy 124, 581-590. doi: 10.1016/j.healthpol.2019.0 3.001

Hansson, S., Arfvidsson, H., and Simon, D. (2019). Governance for sustainable urban development: the double function of SDG indicators. Area Dev. Policy 4, 217-235. doi: 10.1080/23792949.2019.1585192

Hutton, G., and Varughese, M. (2016). The Costs of Meeting the 2030 Sustainable Development Goal Targets on Drinking Water, Sanitation, and Hygiene. Washington, DC: World Bank Group. associated with climate change and help shape city level mitigation strategies.

Along with verifiable datasets for progress monitoring, policymakers need to have a good understanding of the cost implications of achieving the SDGs to efficiently allocate resources. While there had been studies estimating funding needs to achieve SDG goals related to drinking water, sanitation and hygiene at a broad global scale (Hutton and Varughese, 2016), national-level budget estimation to meet urban sustainability goals is difficult as city-level needs are more context-specific. Prakash et al. suggests an innovative method by applying a systematic approach to model the costs of meeting SDG-11 targets in four developing countries.

Meeting urban sustainability goals also vitally depends upon support from local actors and to what extent they are mainstreamed through local development plans. Through a case study of Trinidad, Mycoo and Bharath highlight the difficulties faced by small island countries in translating SDG and NUA from policy goals into practical action due to low administrative capacities and lack of awareness among local political actors. Building local capacities are indeed critical in attaining longterm urban resiliency needs, especially for post-covid rebuilding initiatives, argues Mejía-Dugand et al.. They review existing frameworks for SDG implementation in Bengaluru (India), Medellin (Colombia), and Cape Town (South Africa) and use this to analyze local responses to the Covid-19 pandemic challenges. Based on the analysis, they suggest that for effective SDG implementation it is necessary to stress: multi-level governance, the science-policy interface and citizen, and society engagement.

By critically examining governance challenges and by proposing innovative approaches articles in this special issue contribute to expanding the scope of urban sustainability research. Analysis of various operational challenges impacting city level SDG localization can inform national urban policy processes and can particularly be useful in framing post covid urban resiliency strategies.

\section{AUTHOR CONTRIBUTIONS}

The author confirms being the sole contributor of this work and has approved it for publication. 
United Nations (2021). The Sustainable Development Goals Report 2021. Available online at: https://unstats.un.org/sdgs/report/2021/The-SustainableDevelopment-Goals-Report-2021.pdf (accessed July 09, 2021).

UN-Stats (2015). Global Indicator Framework for the Sustainable Development Goals and Targets of the 2030 Agenda for Sustainable Development. Available online at: https://unstats.un.org/sdgs/indicators/indicators-list/ (accessed May $10,2021)$

Zinkernagel, R., Evans, J., and Neij, L. (2018). Applying the SDGs to cities: business as usual or a new dawn? Sustainability 10:3201. doi: 10.3390/su10093201

Conflict of Interest: The author declares that the research was conducted in the absence of any commercial or financial relationships that could be construed as a potential conflict of interest.
Publisher's Note: All claims expressed in this article are solely those of the authors and do not necessarily represent those of their affiliated organizations, or those of the publisher, the editors and the reviewers. Any product that may be evaluated in this article, or claim that may be made by its manufacturer, is not guaranteed or endorsed by the publisher.

Copyright $\odot 2021$ Chatterji. This is an open-access article distributed under the terms of the Creative Commons Attribution License (CC BY). The use, distribution or reproduction in other forums is permitted, provided the original author(s) and the copyright owner(s) are credited and that the original publication in this journal is cited, in accordance with accepted academic practice. No use, distribution or reproduction is permitted which does not comply with these terms. 